\title{
The Inaugural Year of the Whippoorwill Book Award for Rural YA Literature
}

\author{
The Whippoorwill Committee: Jennifer Sanders, Jill Bindewald, Devon Brenner, \\ Karen Eppley, Kate Kedley, Nick Kleese, Natalie Newsom, Stephanie Short
}

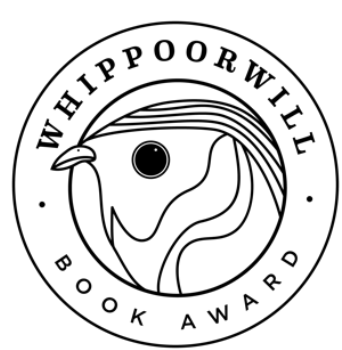

Narratives about American public education often focus on urban settings and the needs of urban students. Similarly, the government bases decisions about school consolidation and pedagogy on research from urban and suburban communities (Eckert \& Alsup, 2015; Tieken, 2014). However, a large number of children live and attend school in rural America: one-fourth of American public schools are rural, and one-fifth of our students attend these schools (Showalter, Klein, Johnson, \& Hartman, 2017). Although rural is certainly not synonymous with deficit, rural students and families do face similar social, economic, and educational challenges as their urban counterparts (Eckert \& Alsup, 2015; Showalter, Klein, Johnson, \& Hartman, 2017). This population deserves focused attention on their specific needs and settings.

Media and popular culture are laden with deficit stereotypes of rural people and places, including stories of small town "deprivation and decline" and "backwoods, backwater, and backward" folk or romanticized depictions of "uncomplicated simplicity," quaint farm-towns, and easy-living (Tieken, 2014, p.7). In addition, Howley and Howley (2010) note that "rural schools are the principal institutions in which young people learn authoritatively to leave rural places" (p.46). Often, well-intending teachers and administrators encourage students to leave their community for "a better life," contributing to the rural flight epidemic. Eckert and Alsup (2015) address the need for teachers to reflect on the stereotypes and prejudices that they may bring into their rural classrooms, whether they are from rural communities themselves or migrate in and out of rural spaces. They work with educators who have articulated "how they moved past the prejudice that they brought with them - preconceived and negative notions of rural people, rural schools, and rural communities - in order to become part of the community in which they teach... creating and pulling on connections made with rural geography through cowboy poetry, with rural community history and current events, with rural perspectives on hunting," and so on (p. x). It is essential to develop explicit counternarratives among educators and with youth about the value in their places and the opportunities to sustain or grow their communities.

Young adult (YA) literature is one place where educators can find such counternarratives or stories depicting multiple, diverse perspectives on rurality, because narratives are a way of knowing the world a way of making sense of our lived experiences (Bruner, 1990; Short, Lynch-Brown, \& Tomlinson, 2018). Our social and cultural worlds shape narratives, and reciprocally, narratives also serve to shape our worlds themselves (DeVitt, 2004). Therefore, it is vital for rural youth (as well as all children) to have literature reflecting their diverse identities and geographies. Additionally, when those narratives are problematic, youth need the skills for critically interpreting and responding to the stories and for creating new narratives.

As teacher educators who taught in rural schools in South Carolina and Florida, we wondered how rural people and places were depicted in contemporary YA literature. When we searched for YA novels that authentically represented rural people and places, we had difficulty finding quality books or recommendation sites. Thus, the Whippoorwill Award for Rural Young Adult Literature emerged as our social action project: to provide classroom teachers with a curated list of high-quality literature with which they can facilitate critical conversations about rurality with their students. Award books must meet the general criteria for excellence in YA literature in its genre. In addition, the literature should portray the values of rural spaces, knowledge, cultures, and histories; represent rural places without overly romanticizing or denigrating them; have an indepth treatment of rural issues, rural sustainability, and/or rural concerns; and contribute to diverse 
representations of people and places. Award titles portray characters and settings accurately and authentically and avoid stereotypes of rural people and places by representing the complexities of the situation, problem, and/or people.

Though these books offer multiple and diverse perspectives on rurality as individual texts and as a set, we recommend that teachers read them with their students through a critical literacy lens. Critical literacy goes beyond critical thinking to interrogate dominant narratives privileged by uncritical readings or acceptance of the text and "correct," literal interpretations often contained in curriculum materials (McDaniel, 2004). Because of the New Criticism movement, English teachers often lead students in reading the text for "objective" meaning rather than searching out the meanings motivated by the author's worldview, the socio-cultural-historical context, and the intended audience. No one text or story can capture all the experiences and voices related to a topic, culture, or social issue, so noticing those gaps and seeking out multiple voices is a powerful practice for understanding others and our world. Critical literacy involves analyzing each of the meanings uncovered to identify inequality, imbalances in power, missing or marginalized identities, and hegemonic ideologies within the text (Mills, 2016). With each book annotation in this article, we have provided critical literacy questions that illuminate marginalized or missing voices from the text, nudge students to consider varied perspectives, or ponder ways the books can spur students into social action.

The official Whippoorwill Award criteria are as follows:

1. The book meets general criteria for excellence in young adult literature in its genre. For example, it addresses universal truths, problems, topics, or issues; leaves a lasting impression or has an enduring quality; utilizes interesting and unique language, style, and/or wordplay; writing is appropriate for a young adult audience of ages 12-18.

2. The literature portrays the value of rural spaces, knowledges, cultures, and histories.

3. The literature represents the reality of rural places without overly romanticizing or denigrating a place.

4. The literature portrays characters and settings accurately and authentically in terms of physical characteristics, social and economic statuses, intellectual abilities, and other human attributes.

5. The literature has an in-depth treatment of issues related to rurality, rural sustainability, and/or rural concerns.

6. The literature avoids stereotypes of rural people and places by representing the complexities of the situation, problem, and/or people.

7. The literature contributes to the body of diverse YA literature by providing representations of diverse people and places.

Below, we provide a brief review of each of the ten 2019 award-winning titles, along with questions to use in secondary classrooms to facilitate critical conversations with students.

If you or your library purchase copies of these books and would like to put the Whippoorwill award seal on the covers, please contact us at jenn.sanders10@okstate.edu or jbindew@okstate.edu for award seals. Include your name and mailing address, and we'll ship you the decals!

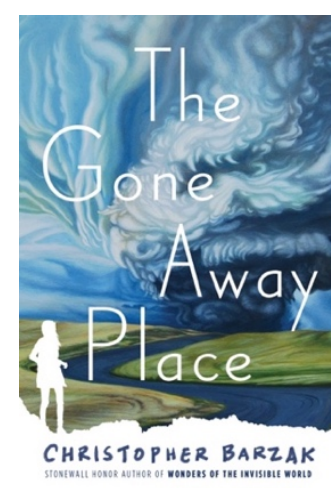

Barzak, Christopher. (2018). The gone away place. New York, NY: Alfred A. Knopf. 289 pgs.

In this tragically beautiful story of a tornado wiping away her small, Ohio town and her closest friends, Ellie struggles through survivor's guilt, repressed grief, and encounters with trapped spirits waiting to be released into the afterlife. She saw it happen; she watched from the lighthouse as the tornado ripped through town and exploded the high school, with her friends inside. While trying to play the "I'm fine" game with herself, Ellie sees the ghosts of friends who died but are trapped in a foggy haze that lingers over the town. Eventually, Ellie stumbles upon the ability to help them tell their final story and transition to the afterlife peacefully. Author Christopher Barzak skillfully depicts the depths of despair and grief that a mid-Western, rural community grapples with after tornadoes devastate their families and homes. (JS) 
Critical literacy questions for classroom conversations:

- The characters in this story have different perspectives on the afterlife, including Japanese traditional beliefs about spirits. What are the different beliefs on death and the afterlife within your family, your friend group, or your classmates? How can we respect and appreciate these different beliefs?

- When a natural disaster strikes a region or community, what are the unique obstacles that remote or rural places face to receiving emergency aid and long-term assistance for recovery? (Perhaps consider places like New Orleans, Louisiana; Puerto Rico; Moore, Oklahoma; and Haiti and the challenges they faced after natural disasters.) How might families with low incomes or who live in poverty be at risk in these situations?

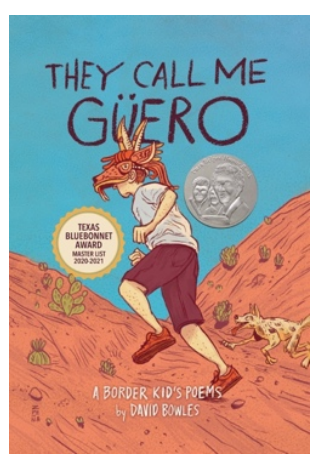

Bowles, David. (2018). They call me Guero: A border kid's poems. El Paso, TX: Cinco Puntos Press. 105 pgs.

Guero is a seventh-grade boy learning to navigate the tough and beautiful worlds of being a borderland kid, with "a foot on either bank" of the Rio Grande. In short, vivid poems, David Bowles lets readers experience the jab of intraracial prejudice, the joys of a group of friends (all named Bobby) with whom Guero can be his nerdy self, and the multifaceted nature of MexicanAmerican cultural identities. Readers familiar with the "borderland" or "valley" region of the TexasMexico divide will find resonance in the landscape descriptions, the folklore, and the ways of being conveyed in this book, and those from other regions will experience an important view of rurality through Guero's life, family, and Mexican-American culture. (JS)

Critical literacy questions for classroom conversations:

- How is this rural borderland community similar to or different from what you picture when you think of "rural?" How is it similar to or different from your community?

- In this story, different images of patriotism and national identity are presented: Guero's mom chooses to keep her Mexican citizenship and not become an American citizen; Guero's grandfather served in the military and has a deep reverence for America; at the border, the family's national identity is implicitly questioned. What are the different perspectives in this story on national identity? Whose voices are unheard? What other perspectives are important to consider?

- Why would Guero be teased or admired for having lighter skin than many of his family members or classmates? What advantages might he receive from having lighter skin? What challenges might he face? Why do these prejudices exist?

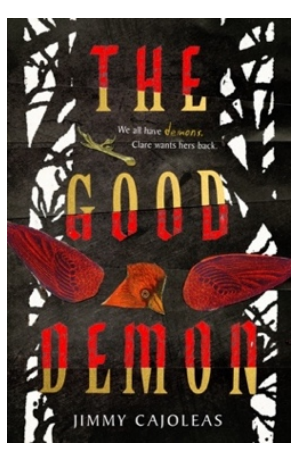

Cajoleas, Jimmy. (2018). The good demon. New York, NY: Amulet Books. 306 pgs.

This gothic tale is set in a place unlike any other, where everyone seems suspiciously rich or poor. An evil history of colonization, the Trail of Tears, a town fire, a Civil War Hospital, and KKK Marches haunts the town, and Clare must unravel its secrets to find the One Wish Man, the only person who can give Clare her demon back. The demon came into her life when she lost her father to drug addiction at age five and was her best friend until the preacher and his son exorcised her. Her one wish is to get her demon back. While she searches for her Only, Clare discovers what it means to live independently of the demon, showing the readers to look within themselves to discover their metaphorical demons and eradicate them to reach true freedom. (JB)

Critical literacy questions for classroom conversations:

- What histories can be told about your place, both good and bad?

- What other ways can people gain power and money other than by magic? Do you notice anything about the ways they gain this power that is similar or different from the characters in the novel?

- Is there someone or something you know (an actual person, business, or substance) who/that may claim to be helping others, but who/that is really harming them? 


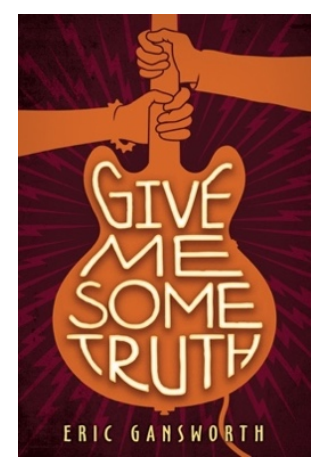

Gainsworth, Eric. (2018).

Give me some truth. New York, NY: Levine, 403 pgs.

One teen longs to leave the Tuscarora Reservation for the city, hoping the upcoming Battle of the Bands can be his ticket out. Another teen has just moved back from the city, working with her mother and sister to sell beadwork to tourists. As Carson and Magpie grow closer together throughout Eric Gainsworth's engaging, highly-textured, and popculture saturated Give Me Some Truth, they also grow more active in their resistance to a local, racist restaurateur. These teen activists and artists offer readers two first-person Native perspectives into daily and ongoing tensions and joys of life on the reservation. They grapple with leaving or staying, family pressures and supports, and the global goingson that provides consistent windows into the musical landscape of the 1980s. (NEK)

Critical literacy questions for classroom conversations:

- Gainsworth's illustrations revise classic rock album iconography. What do these revisions make you think about the pop culture industry? How would you revise them to make a statement about your identities?

- How do Carson and Magpie's respective voices reveal different perspectives on gender? Indigenous identity? Sexuality?

- How are Carson and Magpie's thoughts about their small town similar to and different from your own? What about your identities and experiences impact these comparisons?

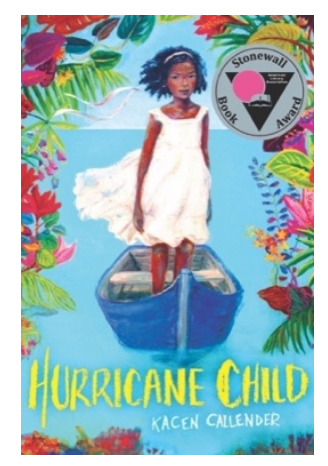

Callendar, Kheryn. (2018). Hurricane child. New York, NY: Scholastic. 214 pgs.

Caroline is twelve years old and was born during the middle of a hurricane on a small Caribbean island in the U.S. Virgin Islands. She takes a water taxi to school on the main island of St. Thomas.

Her mother left her one day and never returned, her teacher and classmates are not kind to her, and Caroline sees people who no one else can see, but
Caroline is full of love. Caroline's friend Kalinda gives her the confidence to stand up to the school bullies, and eventually, Caroline confides in Kalinda regarding both her missing mother and the spirits she can see watching from a distance. After Caroline discovers a secret about their teacher, Kalinda decides to help Caroline find her mother. Through this process, Caroline realizes the love she has for Kalinda may be more than friendship and learns that love and relationships have many complexities, but some feelings are more welcome than others. (KEK)

Critical literacy questions for classroom conversations:

- How does the Caribbean island setting challenge your definition of what it means to live in a rural area?

- Whose stories are typically left out of rural texts, and how does this book (or how doesn't this book) fill that gap?

- How does Caroline understand her love for her mom and Kalinda? What drives that love? How does Caroline understand love with the pain of rejection, especially relative to her mom and Kalinda?

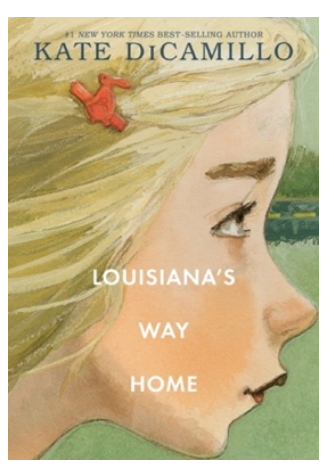

DiCamillo, Kate. (2018). Louisiana's way home. Somerville, MA: Candlewick Press. 240 pgs.

Readers first meet gentle, soft-spoken, insightful Louisiana in the first book of DiCamillo's trilogy. Set in rural Florida and Georgia, book two is Louisiana's story. Forced to find her way, Louisiana leaves behind her beloved Beverly, Raymie, and, eventually, Granny. Louisiana's Way Home speaks to young readers about issues such as poverty, mental health, loss, and resilience as they manifest in Louisiana's life. Adult readers are at once inspired by Louisiana's "grit," outraged at the adults who failed her, and inspired by those who pick her up. But this book was not written for adults. DiCamillo engages her child reader honestly but never overwhelms. She firmly refuses to evoke the rural idyll and, instead, lets Louisiana herself tell readers exactly how things have come to be for her and Granny. At the end of the story, like Louisiana, we are left with questions but are hopeful about her future. (KEE) 
Critical literacy questions for classroom conversations:

- What do you think are some of the most important things to know about Louisiana?

- In what ways is Louisiana able to take control of her life? At various points in the story, what obstacles prevent her from taking control?

- What do you think Louisiana wants from the adults in her life? Why are they or aren't they able to provide what she wants and needs?

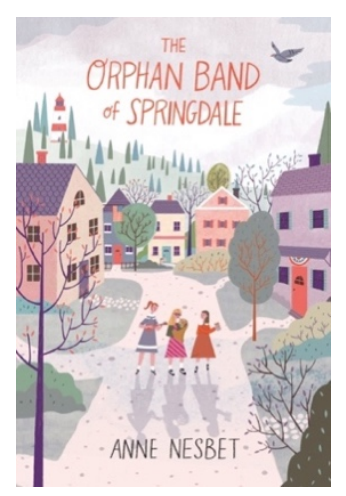

Nesbet, Anne. (2018). The orphan band of Springdale. Somerville, MA: Candlewick Press. 435 pgs.

Set in 1941, this book follows Augusta Neubronner, whose father, a fugitive German labor organizer, puts her on a bus to the rural town of Springdale, Maine, and suddenly leaves to escape the police. Gusta arrives alone to live with family she does not know and must navigate a world that revolves around the local dairy wars, patriotic health certificates, and newfound cousins. Gusta discovers that her uncle was hurt while working at the local mill and is now disabled, unemployed, and unable to afford the surgery he needs. Inspired by hearing her father talk about the union's commitment to the working man, Gusta decides to help her family however she can. This book balances the small battles of a fifth-grade girl's life, such as new eyeglasses and class bullies, with larger ideas of the role of labor unions, the importance of family, and what it means to be a "real" American. (NN)

Critical literacy questions for classroom conversations:

- In what ways do the characters Molly Gowen, Georges Thibodeau, and Mr. Bertmann represent perspectives on what it means to be a "real" American?

- How does the characterization of Mr. Kendall and Mr. Neubronner help the reader understand the text's central idea about the importance of labor unions?

- How does Nesbet explore the perspective of outsiders through the following characters: Josie, Aunt Marion, Mr. Bertmann, and
Augusta? How do these characters defy the status quo, and how does the author's treatment of their otherness reveal themes in the book?

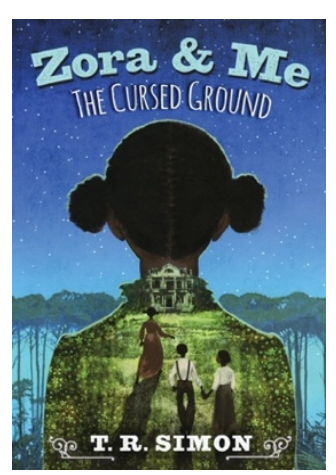

Simon, T. R. (2018). Zora and me: The cursed ground. Somerville, MA: Candlewick, 205 pgs.

"There are two kinds of memory," begins T.R. Simon's Zora and Me: The Cursed Ground. One is the "ordinary kind," and the other is deeper, "rooted in the things you live with, the land you live on, the history of where you belong." In the sequel to the John Steptoe Award-winning Zora and $M e$, Carrie's friendship with a young Zora Neale Hurston continues as they unravel long silent secrets about the history of Eatonville, Florida, the first allBlack township in the United States. Simon provides middle-grade readers with a nuanced contemplation of slavery's lasting effects on rural land ownership, the symbolic power of whiteness, and the forced removal of the Seminole peoples from the land. Eloquent and poignant, The Cursed Ground grants rural educators ample opportunities to discuss race, place, colonization, and language, as well as how these historical forces continue to affect the present. (NEK)

Critical literacy questions for classroom conversations:

- What are some of the long untold stories that Carrie and Zora come to hear? Why weren't these stories told before?

- Who all has claims to the land around Eatonville? What are their reasons?

- In what ways did this novel make you think differently about the histories of your rural place? Or your relationship to that place? 




Smibert, A. (2018). Bone's gift: Ghosts of ordinary objects. Honesdale, PN: Boyds Mills Press. 249 pgs.

After finding an anonymous note, "The gift killed your mother" (p. 26), Bone searches for the contradictory meaning of the word gift. She learns that "gift" took her mother's life, just as she starts to realize her own gift and the responsibility that it precipitates. Bone's Gift displays the fluid complexity of society in an Appalachian mining town in the 1940s, the comfort of place, and the fear of complacency that such comfort can affect. Even while weaving the fantasy of clairvoyant gifts into the story, Smibert depicts the fullness of Appalachia to life through her obvious acquaintance with and dimensional descriptions of place, characters that feel familiar, and language that is realistic enough without being contrived or stereotypical. (SMS)

Critical literacy questions for classroom conversations:

- In Bone's Gift, Bone's father does not want her to know about the clairvoyant gifts her mother's family possesses and tries to prevent her grandmother and uncle from telling Bone about them. Would it have been better for her to know about the gifts before discovering her gift, despite her father's wishes, and why?

- This story shows a dependence between individualism and collectivism and the need to practice and use individual gifts to benefit one's family and community. What individual talent or gift do you possess and practice that is sought out collectively by your family or those around you, and why do people seek you out for that talent/gift? Or what talent or gift do you want to develop that could be of benefit to your community or family?

- Interwoven in the story, formal and informal forms of education are shown to be central to perfecting one's abilities and gifts. For the talent or gift, you just thought of, what are some informal and/or formal ways you educate yourself in developing this gift?

- How might the storyline in this book change if Bone's mother was still living?

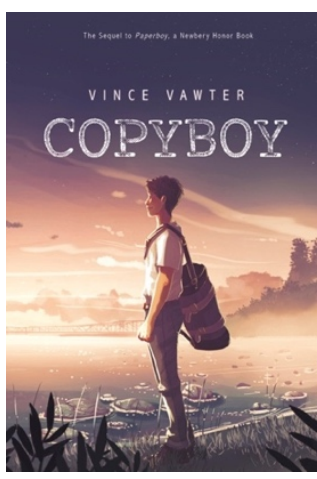

Vawter, Vince. (2018). Copyboy. North Mankato, MN: Capstone Editions. 233 pgs.

Set mostly in the bayous of southeastern Louisiana in 1965, Copyboy takes readers on an adventurous journey from Memphis to the mouth of the Mississippi River. Victor has just graduated from high school with plans to spend the months before college working as a newspaper copyboy. But he must first honor the last request of his mentor and friend, Mr. Spiro, to spread his ashes at the mouth of the Mississippi. This sequel to Vawter's 2014

Newbery Honor Book Paperboy depicts the adventures and hazards that confront Victor; his new friend, Philomene, the smart and brave boat captain; and her Cajun family. Victor and Philomene stare down Hurricane Betsy and consider what it means to live lives tied to the land in the face of a changing economy and climate. (DB)

Critical literacy questions for classroom conversations:

- Philomene needs to decide whether to stay with her family and become a boat captain or head off to college. What would you do? What are the pros and cons of each decision? How would her community and family be affected by each choice?

- How would this book be similar or different if it were set in modern-day instead of 1965 ?

- Victor makes some big decisions for his life at the end of the summer. How does the place he visits impact his sense of himself and his possibilities for the future? 


\section{References}

Bruner, J. (1990). Acts of meaning ( $2^{\text {nd }}$ ed). Boston, MA: Harvard University Press.

Eckert, L. S. \& Alsup, J. (2015). Literacy teaching and learning in rural communities. New York, NY: Routledge.

DeVitt, A. (2004). Writing genres. Carbondale, IL: Southern Illinois University Press.

Howley, C. B. \& Howley, A. (2010). Poverty and school achievement in rural communities: A social-class interpretation. Rural education for the twenty-first century: Identity, place, and community in a globalizing world. Pennsylvania State University, PN: University Park.

McDaniel, C. (2004). Critical literacy: A questioning stance and the possibility for change. The

Reading Teacher, 57(5), p. 472-481.
Mills, K. (2016). Literacy theories for the digital age: Social, critical, multimodal, spatial, material and sensory lenses. Buffalo, NY: Multilingual Matters.

Short, K.G., Lynch-Brown, C.M., \& Tomlinson, C.M. (2018). Essentials of children's literature $\left(9^{\text {th }}\right.$ ed). New York, NY: Pearson.

Showalter, D., Klein, R., Johnson, J., \& Hartman, S. (2017). Why rural matters 2015-2016: Understanding the changing landscape. Report of the Rural School and Community Trust. Retrieved from https://www.ruraledu.org/user_uploads/file/WR M-2015-16.pdf.

Tieken, M. C. (2014). Why rural schools matter. Chapel Hill, NC: The University of North Carolina Press.

\section{Authors and Whippoorwill Award Committee Members:}

Jennifer Sanders, co-chair. Jennifer is the Dresser Endowed Professor of Rural Teacher Education at Oklahoma State University and founding Whippoorwill co-chair. Contact: jenn.sanders10@okstate.edu

Jill Bindewald, co-chair. Jill is a doctoral student at Oklahoma State University in Education - Language, Literacy, and Culture and founding Whippoorwill co-chair. Contact: jbindew@okstate.edu

Devon Brenner, committee member. Devon is Professor of teacher education at Mississippi State University and co-editor of The Rural Educator. Contact: dgb19@msstate.edu

Karen Eppley, committee member. Karen is an Associate Professor of Education at Penn State University. Contact: keh118@psu.edu

Kate Kedley, committee member. Kate is an Assistant Professor in Language, Literacy, and Sociocultural Education at Rowan University in New Jersey. Contact: kedley@rowan.edu

Nick Kleese, committee member. Nick is a doctoral student at the University of Minnesota. Contact: klees023@umn.edu

Natalie Newsom, committee member. Natalie is a high school English teacher at Richmond Hill High School in Georgia. Contact: nbnewsom@gmail.com

Stephanie Short, committee member. Stephanie is adjunct faculty in English at the University of North Georgia. Contact: smshort@ung.edu

\section{Suggested citation:}

Whippoorwill Committee, (2020). The inaugural year of the Whippoorwill Book Award for Rural YA Literature. The Rural Educator, 41(1), 1-7. https://doi.org/10.35608/ruraled.v41i1.984 